\title{
El perfil político de la reina María de Molina*
}

\author{
The political profile of Queen \\ María de Molina
}

CÉsar GonzÁlez MíngueZ**

\begin{abstract}
RESUMEN
Movido por la importancia que en los

últimos tiempos viene alcanzando la biografía y la historia de las mujeres, se ha pretendido fundamentalmente analizar el protagonismo político de una reina singular, María de Molina, una de las figuras reales femeninas más interesantes de toda nuestra Edad Media. De manera especial se ha valorado su papel como mediadora y pacificadora, destacando su alto concepto de la dignidad real y del papel que la realeza debe y puede jugar como árbitro de la llamada «sociedad política», siguiendo una concepción política a la que da nombre, el «molinismo».
\end{abstract}

\section{PALABRAS CLAVE \\ Edad Media, Corona de Castilla, María de Molina, gestión política, molinismo.}

\begin{abstract}
In the context of the growing importance of biography and women's history, the purpose of this article is to assess the political role of a unique queen, María de Molina, one of the most interesting female royal figures of the Hispanic Middle Ages. Specifically, her role as a mediator and a pacifier is examined, stressing her high concept of the royal dignity and of the responsibility that royalty should and must exercise as an arbiter of what is often called political society, following the political concept of «Molinism» that takes its name from this same queen.
\end{abstract}

\section{KEY WORDS}

Middle Ages, Crown of Castile, María de Molina, Political management, Molinism.

* Fecha de recepción del trabajo: 2011-07-14. Fecha de aceptación del trabajo: 2011-11-25.

**Universidad del País Vasco (Vitoria). C.e.: cesar.gonzalez@ehu.es 


\section{APROXIMACIÓN HISTORIOGRÁFICA}

En la escala social en la Edad Media, también antes y después de esa etapa, la condición de reina constituía el más alto honor que se podía alcanzar. Pero su huella en la documentación no guarda relación con la importancia que se les atribuía y no siempre resulta fácil reconstruir su perfil, tanto humano como político, que en principio se le supone ha de tener una cierta relevancia histórica.

En la Corona de Castilla las reinas podían ejercer plenamente como tales, es decir, ser titulares de la Corona, no meramente reinas consortes. Entre las primeras podemos a destacar Urraca, hija y sucesora de Alfonso VI; Berenguela sucesora de su hermano Enrique I aunque cediera inmediatamente la Corona a su hijo Fernando III, o Isabel la Católica, sucesora de Enrique IV. Entre las reinas consortes brilla con luz propia la figura de María de Molina, esposa, madre y abuela de reyes, es decir, de Sancho IV, de Fernando IV y de Alfonso XI, respectivamente.

Una mención especial habría que hacer a las amantes reales, que pudieron en algunos casos ejercer como casi reinas y tener un influencia política muy notable, como pudieron ser Leonor de Guzmán, favorita de Alfonso XI y madre de Enrique II, o María de Padilla, amante que fue de Pedro I, por citar simplemente a dos de las más famosas y conocidas aunque, por supuesto, no las únicas.

Hablar de las mujeres reales, quiero decir, que ejercieron propiamente la realeza o estuvieron estrechamente vinculadas a la misma, en la Corona de Castilla resulta ahora sin duda un tema interesante y de actualidad, que sintoniza bien con la moda historiográfica, acaso más que moda verdadera necesidad, de cultivo del género biográfico, y con el impulso que desde hace unos pocos años ha recibido la historia de las mujeres.

Más que de la mano del gran cronista Fernán Sánchez de Valladolid, que escribió las Crónicas de los reinados de Alfonso X, Sancho IV, Fernando IV y Alfonso $\mathrm{XI}^{1}$, o del también cronista Jofré de Loaysa ${ }^{2}$, podríamos decir que la reina María de Molina entró verdaderamente en la historia escrita y en la cultura popular gracias a la genial obra teatral de uno de nuestros autores clásicos, Tirso de Molina, que convirtió a la reina en protagonista de una de sus más destacadas obras teatrales, y mostró al mismo tiempo un enorme talento al titular la obra pues puso de relieve, precisamente, una de las virtudes que más podemos destacar en ella, la prudencia, que siempre ha sido cualidad muy valorada y útil en la ejecutoria de cualquier político ${ }^{3}$. Al final del segundo acto el dramaturgo hace exclamar a don Diego López de Haro, en un tono abiertamente antifeminista:

1 Crónicas de los Reyes de Castilla, Madrid, 1953, tomo primero.

2 J. DE LOAYSA, Crónica de los Reyes de Castilla Fernando III, Alfonso X, Sancho IV y Fernando IV (1248-1305). Edición, traducción, introducción y notas de Antonio García Martínez, Murcia, 1982, 2ª ed.

3 T. DE MOLINA, La prudencia en la mujer. El condenado por desconfiado, Madrid, 1961, $5^{\mathrm{a}}$ edición. 
«No llegue el tiempo a ofender

tal valor, pues vengo a ver

en nuestro siglo terrible

lo que parece imposible,

que es prudencia en la mujer».

Desde luego el potencial dramático de María de Molina es incuestionable, por «la tensión interna del personaje, su constante lucha interior entre las aparentes flaquezas femeninas y las fuertes presiones políticas a que se vio sometida» ${ }^{4}$. Tirso de Molina escribió una verdadera obra maestra, que resume un modelo dramático de valor universal, en el que una reina viuda se ve asediada por varios aspirantes a su lecho, mientras ella está pendiente sobre todo de defender el trono de su hijo. Cabría pensar seguidamente que semejante punta de lanza hubiera podido servir para proyectar la atención de los historiadores hacia su interesante y compleja personalidad, pero la verdad es que, salvadas las páginas que le dedicó Enrique Flórez en la segunda mitad del siglo XVIII5, tenemos que llegar al siglo pasado para encontrarnos con una gran historiadora, Mercedes Gaibrois, la cual le dedicó algunos trabajos que, a pesar del tiempo transcurrido desde entonces, siguen siendo los fundamentales e imprescindibles para el conocimiento de la trayectoria vital de María de Molina. Me refiero a su discurso de ingreso en la Real Academia de la Historia, que lleva por título Un episodio de la vida de María de Molina ${ }^{6}$, y a dos monografías tituladas, respectivamente, Vidas memorables. María de Molina $^{7}$ y, la más completa, María de Molina. Tres veces reina ${ }^{8}$. Con anterioridad esta misma autora había publicado ya el más completo estudio que existe hasta el momento presente sobre el reinado de Sancho IV de Castilla, esposo de María de Molina ${ }^{9}$. También sobre María de Molina han escrito otros autores, como José María García Rodríguez ${ }^{10}$, Nicolás González Ruiz ${ }^{11}$ o Manuel María de los Hoyos ${ }^{12}$. Posteriormente Luis V. Díaz Martín publicó una breve semblanza de la reina ${ }^{13}$, a la que habría que añadir la monografía más reciente de Rafael del Valle Curieses, en cuyo subtítulo se hace alusión a otra de las virtudes más reconocibles de la reina, el ejercicio de la concordia ${ }^{14}$.

${ }^{4}$ A. RODRíGueZ ARANGO, «María de Molina, reina y personaje dramático», Publicaciones de la Institución «Tello Téllez de Meneses», 36 (1975), p. 66.

${ }^{5}$ E. FLÓREZ, Memorias de las Reynas Cathólicas. Historia genealógica de la Casa Real de Castilla y de León, Madrid, 1761, 2 vols. (Ed. facsimilar, Valladolid, 2002).

6 M. GAIBROIS, Un episodio de la vida de María de Molina, Madrid, 1935.

7 M. GAIBROIS, Vidas memorables. María de Molina, Madrid, 1936.

${ }^{8}$ M. GAIBROIS, María de Molina. Tres veces reina, Madrid, 1967 (Hay una nueva edición crítica, a cargo de Ana del Campo Gutiérrez, Pamplona, 2010).

9 M. GAIBROIS, Historia del reinado de Sancho IV de Castilla, Madrid, 1922-1928, 3 vols.

10 J. M. GARCÍA RODRíGUEZ, Doña María de Molina, Barcelona, 1942.

11 N. GONZÁLEZ RUíZ, Dos madres que salvaron el trono de sus hijos: Blanca de Castilla y María de Molina, Barcelona, 1954.

${ }_{12}$ M. M. DE LOS HOYOS, «Doña María de Molina», Boletín Fernán González, 179 (1972), pp. 290321 y 180 (1973), pp. 626-666.

${ }_{13}$ L. V. DÍAZ MARTÍN, María de Molina, Valladolid, 1984.

14 R. DEL VALLE CURIESES, María de Molina. El soberano ejercicio de la concordia (1260-1321), Madrid, 2000. 
Mercedes Gaibrois fue consciente de la necesidad de no olvidarse de los estudios históricos de carácter biográfico, es decir, los referidos a las personas con nombre propio y auténticos protagonistas de la historia, que sufrían ya un cierto repliegue en aquellos momentos en beneficio de los estudios sobre los conjuntos sociales o protagonistas colectivos, potenciados tanto por el materialismo histórico como por la Escuela de Annales. Anticipándose a su época, hizo una preciosa contribución a la historia de las mujeres, de la que poco o nada se hablaba por entonces, y tuvo el acierto, además, de utilizar la personalidad de la biografiada, la reina María de Molina, para hacernos entender las claves fundamentales de una época ciertamente compleja y enigmática, como fueron los años finales del siglo XIII y los primeros del XIV, que marcan claramente el camino hacia la crisis bajomedieval ${ }^{15}$.

\section{BREVE APUNTE BIOGRÁFICO DE MARÍA DE MOLINA}

Se desconoce dónde y cuándo nació María Alfonso de Meneses, más conocida como María de Molina. Probablemente en algún lugar de Tierra de Campos, espacio que siempre le fue muy familiar, y en torno al año $1260^{16}$. Era hija del infante Alfonso de Molina, hermano de Fernando III el Santo, y de su tercera mujer, doña Mayor Alfonso de Meneses. En junio de 1282 contrajo matrimonio en Toledo con el infante don Sancho, futuro Sancho IV, hijo de Alfonso X el Sabio. Sancho IV prefirió a María de Molina, de la que estuvo verdaderamente enamorado, a Guillerma de Moncada, candidata que le había preparado Alfonso X y que tenía tanta fama de rica ${ }^{17}$ como de fea y brava ${ }^{18}$. Los contrayentes eran parientes en tercer grado, pues María de Molina era prima carnal de Alfonso X y por tanto tía segunda de Sancho IV y se habían casado sin la oportuna dispensa papal. El papa Martín IV al tener noticia del matrimonio escribió una dura carta a Sancho IV, fechada en Orvieto el 13 de enero de 1283, calificándolo de "excessus enormitas», «incestas nuptias» y "publica infamia», ordenándole que se separase inmediatamente de su mujer bajo pena de excomunión y entredicho. A partir de este momento se iniciará una auténtica batalla diplomática para conseguir la dispensa papal, aunque Sancho

15 M. GAIBROIS, María de Molina..., p. 15. Sobre la coyuntura castellana en torno a 1300 puede consultarse C. GONZÁLEZ MÍNGUEZ, «Poder real, poder nobiliar y poder concejil en la Corona de Castilla en torno al año 1300», Publicaciones de la Institución «Tello Téllez de Meneses», 71 (2000), pp. 39-72; C. GONZÁLEZ MÍNGUEZ y H. URCELAY GAONA, «La crisis bajomedieval en Castilla durante el reinado de Fernando IV a través de las reuniones de Cortes (1295-1312)", Acta Historica et Archaeologica Mediaevalia, 26 (2005), pp. 285-305 y C. GONZÁLEZ MíNGUEZ y R. PALACIOS, «Reflexiones sobre la crisis demográfica en la Corona de Castilla durante el reinado de Fernando IV (1295-1312)», Estudos em Homenagem ao Professor Doutor José Marques, Porto, Faculdade de Letras da Universidade do Porto, 2006, vol. 1, pp. 453-464.

16 R. DEL VALLE CURIESES, María de Molina..., pp. 33-34.

17 Guillerma de Moncada era una «de les honrrades doncellez que filla de rey no fos, que fos en Espanya». R. DE MUNTANER, Crónica catalana, ed. de A. Bofarull, Barcelona, 1860, cap. CLXXIII.

${ }_{18}$ «...era tenida por mujer muy brava y era muy fea, que tenía gran estado en Cataluña y Aragón». J. ZURITA, Anales de la Corona de Aragón, Zaragoza, 1610, vol. I, fol. 274r. 
IV morirá el 25 de abril de 1295, antes de que fuera otorgada la misma ${ }^{19}$. Esa batalla tuvo que continuarla después en solitario María de Molina pues era imprescindible conseguir el reconocimiento de la legitimidad de los hijos habidos en el matrimonio, cuestión que afectaba especialmente a Fernando IV, heredero y sucesor de Sancho IV, y que será uno de los argumentos en que descansa la guerra civil con que se inicia su reinado ${ }^{20}$.

Cuando contrajo matrimonio con Sancho IV, María de Molina era una joven bella y sencilla, cuya vida trascurría tranquila en el amplio escenario de Tierra de Campos. Su marido, apodado El Bravo, era, por el contrario, de carácter impetuoso y hasta violento con frecuencia, y antes de casarse había tenido ya relaciones ilícitas con María de Meneses de Ucero, de las que había nacido una hija, de nombre Violante. Fuera del matrimonio tuvo también otro hijo, Alfonso Sánchez, aunque no se sabe el nombre de la madre ${ }^{21}$.

Los relatos cronísticos nos permiten intuir con bastante claridad una imagen de María de Molina como una mujer frágil, de profundas convicciones y de salud un tanto endeble pues estuvo enferma con frecuencia, lo cual no fue obstáculo para que en el arco cronológico de 1283 a 1293 diera a luz siete hijos: Isabel, la primogénita, Fernando, que reinará como IV de ese nombre, Alfonso, Enrique, Pedro, Felipe y Beatriz, que fue reina de Portugal ${ }^{22}$.

Las primeras gestiones políticas realizadas por María de Molina, aunque no dieran los resultados positivos esperados, estuvieron encaminadas a la búsqueda del entendimiento, la paz y el perdón entre Alfonso X y su hijo Sancho IV, que se había sublevado contra el legítimo soberano ${ }^{23}$. Al referirse brevemente a ellas Mercedes Gaibrois definió de manera magistral dos de los rasgos que acompañarán la singular ejecutoria vital de María de Molina: «La mujer de Sancho el Bravo empezaba su actuación política como pacificadora, y ésa habría de ser siempre su misión. María Alfonso de Meneses poseía el don de la concordia» ${ }^{24}$. Y todo ello conducido siempre con singular prudencia.

El curso de la vida de María de Molina concluyó en Valladolid, el día primero de julio de 1321. Dos días antes, el 29 de junio, dictó a Pedro Sánchez, escribano de Valladolid, su segundo y definitivo testamento, el primero lo redactó en 1308, en el

19 A. MARCOS POUS, «Los dos matrimonios de Sancho IV de Castilla», Cuadernos de Trabajos de la Escuela Española de Historia y Arqueología en Roma, VIII (1956), pp. 1-108.

${ }_{20}$ Sobre el reinado de Fernando IV pueden consultarse dos monografías que brindan una visión completa del mismo: C. GONZÁLEZ MínGUEZ, Fernando IV de Castilla (1295-1312). La guerra civil y el predominio de la nobleza, Vitoria, 1976, y Fernando IV.1295-1312, Palencia, 1995. La obra clásica sobre el reinado es la de A. BENAVIDES, Memorias de D. Fernando IV de Castilla, Madrid, 1860, 2 vols., con imprescindible apéndice documental.

${ }^{21}$ E. FLÓREZ, Memorias de las Reynas..., vol. II, pp. 547-549.

22 E. FLÓREZ, Memorias de las Reynas..., vol. II, pp. 537-542.

${ }^{23}$ M. GONZÁLEZ JIMÉNEZ, Alfonso X. Historia de un reinado. 1252-1284, Burgos, 1999, 2ª ed., pp. $165-211$.

${ }^{24}$ M. GAIBROIS, María de Molina..., p. 22. 
que a través de sus mandas y perdones da buena prueba de su grandeza moral25. Sus restos mortales descansan en un sepulcro de alabastro, situado en el centro del crucero de la iglesia conventual de las Huelgas Reales de Valladolid ${ }^{26}$.

\section{CARACTERÍSTICAS DE LA GESTIÓN POLÍTICA DE MARÍA DE MOLINA.}

Seguir con detalle la dilatada actividad política de María de Molina de alguna forma equivaldría a repasar en su integridad los reinados completos de Sancho IV y de Fernando IV y los nueve primeros años del largo reinado de Alfonso XI, período en el que fue punto de referencia inexcusable de la política castellana ${ }^{27}$. Para la presente ocasión me ha parecido más oportuno ofrecer simplemente algunas pinceladas, que descansan en las aportaciones cronísticas de Fernán Sánchez de Valladolid y de Jofré de Loaysa y en la semblanza que sobre la misma hiciera Enrique Flórez, y que de alguna forma ilustran la sorprendente capacidad política de la reina, expresión de una rica personalidad llena de muy variados matices.

Cuando Flórez inicia el relato sobre María de Molina dice que es la primera en la nómina regia en llamarse María y no duda en apodarla «la Grande»28. Al referirse a la compleja negociación para conseguir las bulas de legitimación insiste en las «proezas de esta gran mujer», cuyas acciones más parecen propias de un auténtico héroe ${ }^{29}$. Permanentemente actuó como leal consejera de Sancho IV ${ }^{30}$, apareciendo siempre en sus intervenciones como «prudentísima señora» ${ }^{31}$. A pesar de su frágil salud, fue mujer de extraordinaria fortaleza a la hora de tomar decisiones, huyendo siempre de la violencia: «la Reyna, cuyo corazón no conoció desmayos, manifestó un espíritu no sólo superior a su sexo, sino labrado en el yunque y oficina de los Héroes. Ni descaeció en la empresa, al mostrarse más ardua; ni pensó en valerse de las armas» ${ }^{32}$. Sorprende y causa la admiración de todos, igualmente, su enorme capacidad de trabajo: «La aplicación, el zelo, y la constancia en el despacho era tal, que solía estar desde la mañana hasta las tres de la tarde, sin comer, y sin menearse, admirándose todos de cómo tenía aguante para

25 A. BENAVIDES, Memorias de D. Fernando IV de Castilla, Madrid, 1860, vol. I, pp. 680-686. Un análisis del testamento, poniendo de relieve los recursos del poder regio y su distribución, en C. ESTEPA DÍEZ, «Dos testamentos femeninos en el siglo XIV: María de Haro y la reina María de Molina», en C. M. REGLERO DE LA FUENTE (Coord.), Poder y sociedad en la Baja Edad Media Hispánica. Estudios en homenaje al profesor Luis Vicente Díaz Martín, Valladolid, 2002, vol. I, pp. 375-391. También M. LARRIBA BARCIERO, «El testamento de María de Molina», Signo, 2 (1995), pp. 201-211.

26 R. DEL VALLE CURIESES, María de Molina..., p. 281.

27 F. GÓMEZ REDONDO, Historia de la prosa medieval castellana. I. La creación del discurso prosístico: el entramado cortesano, Madrid, 1998, p. 859.

28 «En el nombre es la primera de nuestras Reynas: y aunque el orden no la huviera dado la primacía, se la grangearan sus proezas, que no la permitieran ser segunda en ninguna línea, haciéndola en todas grande». E. FLÓREZ, Memorias de las Reynas..., vol. II, pp. 534-535.

29 E. FLÓREZ, Memorias de las Reynas..., vol. II, pp. 543-544.

30 E. FLÓREZ, Memorias de las Reynas..., vol. II, p. 545.

31 E. FLÓREZ, Memorias de las Reynas..., vol. II, pp. 551 y 571.

32 E. FLÓREZ, Memorias de las Reynas..., vol. II, p. 552. 
tanto, y saliendo todos no menos satisfechos de su zelo, y de la rara prudencia con que despachaba los negocios» 3 .

Los elogios de Flórez a María de Molina son constantes y no escatima todo tipo de calificaciones positivas, como la de «honestísima señora», cuando se niega a contraer nuevo matrimonio con el infante don Pedro de Aragón como le proponía interesadamente el infante don Enrique ${ }^{34}$, o el de «astuta», cualidad de la que hasta cierto punto no debe carecer un político, y que era necesaria emplear para neutralizar las peligrosas maniobras del infante don Enrique, siempre más preocupado por atender sus propios intereses que los del reino, mientras que, contrariamente, la reina «miraba mejor por el bien de los pueblos" ${ }^{35}$. En otro momento, cuando la reina trataba de negociar para conseguir el apoyo de don Enrique, Flórez dice de ella que era «fidelísima y prudentísima Señora» ${ }^{36}$.

En general, en su actuación frente a la nobleza María de Molina puso bien de manifiesto su enorme talla política, pues era "capaz de batirse con todos", utilizando sabiamente el estímulo de los premios o el freno de los castigos, como se puso bien de manifiesto, por ejemplo, en $1298^{37}$. Sin duda, uno de los personajes que más debería haber estado agradecido a la reina es su indigno e intrigante cuñado, el infante don Juan, al que al menos en dos ocasiones libró de la muerte a manos de Sancho IV (Alfaro, 1288) y de Fernando IV (Burgos, 1311), respectivamente ${ }^{38}$. No podemos olvidar la permanente actitud apaciguadora o pacificadora que desplegó reiteradamente hacia la nobleza, aunque algunos de los más conspicuos representantes de la misma, como el infante don Enrique, el infante don Juan, don Juan Núñez de Lara, don Juan Manuel y otros, conspiraran abiertamente contra ella en más de una ocasión ${ }^{39}$, pues entendía que sólo desde esa posición era posible conservar el trono de Fernando $\mathrm{IV}^{40}$, objetivo siempre presente en las todas actuaciones de María de Molina, a pesar de que el comportamiento del rey hacia su madre no fuera el que en justicia correspondía ${ }^{41}$.

Aunque el peso principal de las negociaciones que precedieron a la firma de la sentencia arbitral de Torrellas (1304) correspondió al infante don Juan y a Jaime II de Aragón ${ }^{42}$, durante todo su recorrido y posteriormente a la firma María de Molina

${ }^{33}$ E. FLÓREZ, Memorias de las Reynas..., vol. II, p. 552.

34 E. FLÓREZ, Memorias de las Reynas..., vol. II, p. 557.

35 E. FLÓREZ, Memorias de las Reynas..., vol. II, p. 561.

36 E. FLÓREZ, Memorias de las Reynas..., vol. II, p. 575.

37 E. FLÓREZ, Memorias de las Reynas..., vol. II, pp. 563-564.

38 E. FLÓREZ, Memorias de las Reynas..., vol. II, pp. 545 y 579.

39 E. FLÓREZ, Memorias de las Reynas..., vol. II, pp. 566-567.

40 E. FLÓREZ, Memorias de las Reynas..., vol. II, p. 572.

41 A la frecuente deslealtad de Fernando IV hacia su madre, ésta respondió siempre con gran altura de miras: «Pisando su invencible pecho todo aquel tropel de combates, dio al mundo el raro egemplo, no ya de política civil, sino de heroyca virtud, y de aquella envidiable perfección que reyna en los corazones más generosos, de corresponder al mal con bien». E. FLÓREZ, Memorias de las Reynas..., vol. II, p.574.

${ }^{42}$ C. GONZÁLEZ MíNGUEZ, «Fernando IV de Castilla (1295-1312): Perfil de un reinado», Espacio, Tiempo y Forma, Serie III, Historia Medieval, 17 (2004), pp. 230-235. 
mostró su habilidad en las artes de la política e hizo gala de ese permanente «amor a la paz», pero también de su gran arte, discreción y gracia natural, a pesar de su delicado estado de salud en aquellos momentos ${ }^{43}$.

María de Molina utilizó a fondo sus virtudes pacificadoras y apaciguadoras para frenar los ímpetus violentos de su marido Sancho IV pero también para mantener una discreta pero cordial relación con su nuera, la reina doña Constanza, mujer de Fernando IV, que hasta cierto punto quedó eclipsada por la potente personalidad de María de Molina ${ }^{44}$.

En su larga trayectoria política María de Molina siempre tuvo presente la defensa de los «bienes de la Corona» y del «bien común» ${ }^{45}$, con frecuencia codiciados por las insaciables ambiciones de la nobleza. En las Cortes de Medina del Campo de 1302, las primeras que reunió Fernando IV tras ser proclamado mayor de edad, el infante don Juan y don Juan Núñez de Lara acusaron a María de Molina de mala administración durante los años de la minoría y de haberse quedado con importantes sumas de dinero. Nada consiguieron demostrar contra la reina, quien hizo una solemne defensa de su correcto comportamiento, pues «jamás se apartaría de los interesses de su hijo, porque esso sería, demás de malograr lo mucho que por él havía padecido, dar mal egemplo al mundo, poniendo borrón en sus procedimientos, y que estaba resuelta a padecer por el Rey aquello, y mucho más que maquinasen contra ella, antes que degenerar en la cosa más mínima»46.

En la defensa del trono de Fernando IV, como pasará después con su sucesor Alfonso XI, María de Molina contará con el inestimable apoyo de los concejos, única fuerza, ahora potenciada a través de la constitución de hermandades generales ${ }^{47}$, que era capaz de equilibrar hasta cierto punto el predominio nobiliar. Cuando el infante don Juan convocó un ayuntamiento concejil en Palencia en 1296, María de Molina se movió con enorme inteligencia política para conseguir que los concejos enviaran a la reunión como representantes a personas completamente leales y partidarias de Fernando IV ${ }^{48}$. Se trataba de una medida de claro signo intervencionista, pero que luego sería frecuentemente utilizada por los monarcas posteriores, pues era la mejor manera de asegurarse la mayor docilidad de los procuradores concejiles.

Flórez describe con extremo laconismo la tremenda sensación de orfandad que se percibió en el reino tras el fallecimiento de María de Molina, dada «la grandeza de la madre que perdían», pues no en vano sus «hombros habían sostenido en paz la máquina de tan crecidos Reynos» ${ }^{49}$. Desde luego Flórez no oculta su gran

${ }^{43}$ E. FLÓREZ, Memorias de las Reynas..., vol. II, pp. 577-578.

44 E. FLÓREZ, Memorias de las Reynas..., vol. II, p. 580.

45 E. FLÓREZ, Memorias de las Reynas..., vol. II, pp. 565 y 586.

46 E. FLÓREZ, Memorias de las Reynas..., vol. II, p. 572.

47 C. GONZÁLEZ MÍNGUEZ, «La participación concejil en la estructura de poder de la Corona de Castilla durante el reinado de Fernando IV (1295-1312)», en F. FORONDA y A. I. CARRASCO MANCHADO (Dirs.), El contrato político en la Corona de Castilla. Cultura y sociedad políticas entre los siglos $X$ al XVI, Madrid, 2008, pp. 97-121.

48 E. FLÓREZ, Memorias de las Reynas..., vol. II, pp. 554-555. 
simpatía por María de Molina, como bien lo manifiesta en el elogio final que hace de la reina: «De suerte que ni las grandes atenciones de la Corona, ni los gravísimos negocios de aquel tiempo pudieron distraerla de lo sagrado: antes bien teniendo fija la vista en la causa de Dios y de la Iglesia, logró la firmeza imponderable, con que sin ladearse a la vanidad de la cumbre mundana, ni bacilar en las turbulencias temporales, miraba como único norte lo más recto, midiéndolo por las Leyes Divinas, y ordenando todo a la mayor seguridad de sus vasallos. Digna de que la intitulemos muger fuerte, probada y acrisolada en tres Reynados, cada uno a qual más llenos de turbulencias, golfos de tempestades continuas, bageles agitados de borrascas, pero libres del naufragio por el brazo de una muger, aplicado no al timón solamente, sino al remo: luchando no menos contra las olas de los enemigos, que contra la infidelidad de sus aliados: intitulada muger, para que resalte el acero de un pecho varonil: madre una vez de su hijo D. Fernando, pero mil veces madre a costa de mil dolores en conservarle el Reyno. Sufrida en tolerar desayres del marido. Vencedora hasta en las ingratitudes del hijo. Unos y otros, quando la seguían, acertaban; tropezaban al apartarse de ella: era pues como pauta del acierto. $Y$ aunque no hemos individualizado los muchos passos que dio (pues esto necesitaba copiar Chrónicas enteras) los vestigios apuntados denotarán lo grande del Gigante. Egemplo tienen los Reyes y las Reynas» ${ }^{50}$.

La Crónica de Jofré de Loaysa comprende de 1248 a 1305 y, en general, es sumamente lacónica al narrar los acontecimientos. Aunque no transmita con detalle todo el protagonismo ejercido por María de Molina, si espigamos bien en su relato nos damos cuenta inmediatamente de la simpatía que siente el autor hacia la reina, pues siempre que le cita aparece mencionada con los más elogiosos epítetos: «noble señora» le llama cuando contrae matrimonio con Sancho IV ${ }^{51}$; « ilustrísima reina» en los momentos inmediatos a la tragedia de Alfaro52; «ilustre reina... y señora de virtud digna de alabanza y, más aún, de admiración $n^{253}$, en los trágicos momentos de los funerales en Toledo por el alma de Sancho IV; «ilustre reina..., señora sapientísima ${ }^{34}$, dice de ella cuando se entrevista en Alcañices con el rey Dionís de Portugal, donde se celebraron los esponsales entre Fernando IV, aún niño, y la infanta portuguesa doña Constanza.

Pero la virtud que más atribuye Jofré de Loaysa a María de Molina es la de la prudencia: "muy prudente y circunspecta» ${ }^{55}$ dice de ella cuando estaba en las Cortes de Valladolid de 1295, en un momento especialmente difícil en el primer año del reinado de Fernando IV; «firme y prudente» ${ }^{56}$, le llama en los momentos que

49 E. FLÓREZ, Memorias de las Reynas..., vol. II, p. 588.

50 E. FLÓREZ, Memorias de las Reynas..., vol. II, pp. 590-591.

51 J. DE LOAYSA, Crónica de los Reyes de Castilla..., p. 117.

52 J. DE LOAYSA, Crónica de los Reyes de Castilla..., p. 131.

53 J. DE LOAYSA, Crónica de los Reyes de Castilla..., p. 163.

54 J. DE LOAYSA, Crónica de los Reyes de Castilla..., p. 191.

55 J. DE LOAYSA, Crónica de los Reyes de Castilla..., p. 165.

56 J. DE LOAYSA, Crónica de los Reyes de Castilla..., p. 181. 
precedieron al asedio de Mayorga de Campos en 1296. Inmediatamente después de dicho asedio María de Molina se encontró prácticamente desasistida de cualquier leal apoyo nobiliar y con el reino muy afectado por los graves daños y destrucciones provocados ya por la guerra civil. Sobre ese panorama de fondo Loaysa hace el más encendido elogio de la reina subrayando sus innatas cualidades políticas: "con su gran tacto y prudencia, casi sola, acertadamente gobernaba como mejor podía al rey y a su tierra, porque casi todos los barones se habían pasado a las filas enemigas, excepto don Diego [López de Haro]", y un poco más adelante nos subraya cómo María de Molina actuando con «sencillez y sagaci$d_{a d}{ }^{57}$, bien pagando soldadas o haciendo promesas mayores, fue consiguiendo que muchos nobles volvieran a la fidelidad del rey Fernando IV. Cuando el joven monarca, poco después de ser proclamado mayor de edad, a primeros de diciembre de 1301, cayó bajo la siniestra influencia del infante don Juan y de don Juan Núñez de Lara, éstos le manejaron a su antojo separándole del «prudente consejo de su madre, que por guardar su vida y su reino tantos y tan grandes peligros había sufrido" ${ }^{58}$, y que tuvo que padecer en estos momentos la terrible ingratitud de su hijo.

Es evidente que para el cronista Jofré de Loaysa la reina María de Molina posee unas excelentes cualidades para actuar como un buen político, es decir, nobleza, prudencia, sagacidad, sabiduría y don de consejo, que siempre ejercerá con indudable maestría. Sin duda, unas herramientas imprescindibles para moverse con cierta facilidad, o mejor habilidad, en la complicada época que le tocó vivir.

De las cuatro crónicas que escribió Fernán Sánchez de Valladolid ${ }^{59}$ es evidente que en la que ejerce María de Molina un mayor protagonismo es en la que corresponde al reinado de Fernando IV, y es en ella donde podemos encontrar un mayor número de referencias y de calificaciones, todas ellas de tono laudatorio. En general, cuando es citada, sobre todo en la crónica de su hijo, aparece como la «noble reina» ${ }^{60}$. También se subraya que era «mujer de grande entendimiento» ${ }^{61}$. A pesar de su condición de mujer, María de Molina tenía un carácter fuerte ${ }^{62}$, capaz de infundir verdadero miedo, por ejemplo, a un noble tan poderoso como don Juan Núñez de Lara ${ }^{63}$, al tiempo que, tomada una decisión, se mantenía siempre muy firme en sus convicciones ${ }^{64}$. Tenía también una extraordinaria capacidad de trabajo, incluso cuando estaba enferma circunstancia que solía repetirse con fre-

57 J. DE LOAYSA, Crónica de los Reyes de Castilla..., p. 185.

58 J. DE LOAYSA, Crónica de los Reyes de Castilla..., p. 207.

59 S. DE MOXÓ, «El patrimonio dominical de un consejero de Alfonso XI. Los señoríos de Fernán Sánchez de Valladolid», Revista de la Universidad Complutense, vol. XXII, núm. 85 (1973), pp. 123-162.

60 «Crónica de Fernando IV», pp. 93, 95, 97, 101, 102, 103, 104, 105, 106, 107, 108, 110, 111, 114,

117, 119, 121, 145, 146, 147 y 164. «Crónica de Alfonso XI», pp. 183 y 184.

61 «Crónica de Fernando IV», pp.75, 89 y 96.

62 "Crónica de Fernando IV», p. 109.

63 "Crónica de Fernando IV», p. 109.

64 «...e por esta razón que vieron que lo avía ella mucho a corazón e que la non podían mudar dello en ninguna manera». "Crónica de Fernando IV», p. 104. 
cuencia, como se hizo bien patente durante el sitio de Paredes de Nava en $1296^{65}$. En alguna ocasión se la define como «muy mesurada» ${ }^{66}$ y también como enemiga de la injusticia, como puso de manifiesto al mostrar su gran malestar por las arbitrariedades del infante don Enrique, al que el cronista llama con acierto «gran bolliciador $>{ }^{67}$, cuando ordenó sin motivo justificado la muerte de dos personas en Zamora para apoderarse de sus bienes ${ }^{68}$. En Almazán, en otro momento, vemos personalmente a María de Molina administrar justicia y castigar a los malhechores: "otrosí mandó derribar en tierra de Almazán veinte y cuatro casas muy fuertes que y avía de que se facía mucho mal en toda esa tierra, e fizo justicia en muchos lugares e en muchos omes que falló malhechores» 69 .

Acaso una de las cualidades de María de Molina que más impactaron al cronista Fernán Sánchez de Valladolid fue su capacidad negociadora, se podría decir que incansable, y la búsqueda permanente de la concordia y el «asosegamiento», por utilizar una expresión de la época, y que hubo de utilizar siempre para contener las excesivas ambiciones nobiliarias, que tantas veces pusieron en peligro tanto el trono de Fernando IV y como el de Alfonso XI. Son innumerables las veces que negoció con el infante don Juan, con Juan Núñez de Lara, con Diego López de Haro y con otros destacados nobles, buscando siempre la paz, la defensa de los intereses generales del reino, el servicio del rey y el beneficio de la Corona ${ }^{70}$.

María de Molina fue una reina popular, en el sentido de ser querida y admirada por el pueblo llano. Por ello no sorprende en absoluto que fueran los concejos los que más respaldaran sus iniciativas de gobierno a través de las Cortes y mediante la concesión de los servicios correspondientes ${ }^{71}$. En cualquier caso, y para evitar sorpresas, siempre tuvo especial cuidado en orientar el nombramiento de los representantes ciudadanos a Cortes entre aquellas personas que le eran especialmente fieles y leales: «envió ende apercibir a los omes en cada lugar, e envioles decir que guisasen en commo los que oviesen de enviar a este ayuntamiento de Palencia que fuesen aquellos omes de quien ella fiaba, e enviábalos luego nombrar por nombre»> ${ }^{72}$. María de Molina no sólo elige a los representantes populares que acuden a las Cortes sino

65 «E la noble reina doña María punaba de acuciar a los de la hueste commo combatiesen la villa; $e$ ellos estando en la cerca, adoleció la Reina muy mal de una nascencia que le nasció en el brazo, e durole diez semanas con muy gran dolor, e non dejaba por eso de librar todos los pleitos que y venían de todos los reinos e otrosí de estar cada día en corte con todos los que eran en la hueste, e de fablar con ellos e rogalles que sirviesen al Rey su fijo». "Crónica de Fernando IV», p. 105.

66 «Crónica de Fernando IV», p. 103.

67 «Crónica de Fernando IV», p. 94.

68 «Crónica de Fernando IV», p. 114.

69 «Crónica de Fernando IV», p. 162.

70 «Crónica de Sancho IV», p. 84; «Crónica de Fernando IV», pp. 96, 100, 134, 145, 146, 149,157 y 168, y «Crónica de Alfonso XI», pp. 188-191.

${ }_{71}$ Baste un ejemplo: «E los de la tierra leyendo commo la noble Reyna obraba muy bien, tovieron todos por muy grand derecho de facer todo cuanto ella demandaba aguisado e con razón, e luego dieron al Rey cuatro servicio para pagar los fijosdalgo, e uno para la legitimación del Rey e de los otros sus fijos». «Crónica de Fernando IV», p. 119.

72 «Crónica de Fernando IV», p. 97. 
que les orienta sobre los acuerdos que deben tomar en las mismas, siempre a mayor honra del rey y de su señorío, como se vio muy claramente en las Cortes de Valladolid de $1307^{73}$. Constantemente María de Molina buscó y obtuvo el apoyo de los concejos, en general, y gracias al mismo, por ejemplo, consiguió que en 1298 don Dionís de Portugal se retirara de Castilla, donde había venido con aire invasor más que a apoyar a Fernando IV a negociar con el infante don Juan y el infante don Enrique sobre un posible reparto de los reinos ${ }^{74}$.

María de Molina fue una hábil administradora. El cronista Fernán Sánchez de Valladolid dice en una ocasión de ella que «traía la facienda del Rey su fijo tan bien e tan cuerdamente e con tan gran recabdo ${ }^{75}$, pero no se puede dejar de tener en cuenta en estos momentos que la falta de recursos es asfixiante, dada la coyuntura económica general, los cuantiosos gastos de la guerra y las permanentes demandas de los nobles, entre otras cosas. Por ello tuvo necesidad de acudir a Burgos en varias ocasiones para conseguir préstamos de los mercaderes burgaleses para poder pagar las soldadas de los nobles ${ }^{76}$, pues los servicios aprobados por las Cortes resultaban totalmente insuficientes.

Es evidente que María de Molina gozó de un alto prestigio internacional, tanto en el ámbito peninsular como europeo ${ }^{77}$. En el primero manteniendo unas complejas relaciones con don Dionís de Portugal y con Jaime II de Aragón, ambos de enorme talla política, cuyas ambiciones trató de frenar. A don Dionís consiguió apartarle de las peligrosas complicidades con el infante don Juan y don Alfonso de la Cerda, perpetuos aspirantes al trono de Castilla. Con respecto a Jaime II no po-

73 «E luego que la Reina ovo esto puesto con el infante don Juan, fablolo con el Rey, e él tóvolo por bien, e tomó manera para fablar con todos los de las villas que y eran, e punó de los tirar de aquella carrera en que estavan, e díjoles que las cosas que ellos querían pedir, que ella quería ser con ellos en las pedir; e commo quier que ellos las sabían todas, que ella su parte sabía de las cosas que a ellos cumplían e ella entendía que eran servicio de Dios e pro de toda la tierra. E cuando ellos esto oyeron a la Reina plogoles ende mucho, porque sabían e eran ciertos que ella era la que quería pro de toda la tierra, e que ficiera mucho por ella, e que avía tomado muy grand afán e grand lacería por facer reinar al Rey su fijo, e por guardar la tierra de daño e de mal lo más que ella pudo; e estonce acordaron e dijeron que lo farían, e que les placía, e pidiéronle por merced que lo ficiese así; e luego acordaron con la Reina las peticiones que querían facer al Rey; e en aquello que la Reina entendía que era daño del Rey e del reino, tiroles dello con razones derechas que les dijo, que ellos entendieron que era así, e en las otras cosas ordenoles commo las demandasen guardando la honra del Rey e del su señorío, e lo más pro de la tierra que pudo». «Crónica de Fernando IV», pp. 150-151.

74 «Crónica de Fernando IV», p. 112.

75 «Crónica de Fernando IV», p. 110.

76 «Crónica de Fernando IV», pp. 108 y 118.

77 Una breve síntesis sobre la política exterior de Castilla en el reinado de Fernando IV en C. GONZÁLEZ MíNGUEZ, «Fernando IV de Castilla (1295-1312): Perfil de un reinado», Espacio, Tiempo y Forma, Serie III, Historia Medieval, 17 (2004), pp. 242-244.

78 J. M. DEL ESTAL GUTIÉRREZ, Conquista y anexión de las tierras de Alicante, Elche, Orihuela y Guardamar al reino de Valencia por Jaime II (1296-1308), Valencia, 1982; El reino de Murcia bajo Aragón (1296-1305). Corpus Documental, Alicante, 1985 y 1990, 2 vols. y «El itinerario de Jaime II de Aragón en la conquista del reino castellano de Murcia (1296-1301)», Anales de la Universidad de Alicante, núm. 11 (1996-1997), pp. 135-172. Destacan, igualmente, los trabajos de M. T. FERRER I MALLOL, «Notes sobre 
demos olvidar que pasó de conquistar el reino de Murcia a ser, a partir de 1305, leal colaborador en la lucha contra los musulmanes granadinos ${ }^{78}$.

En cuanto al ámbito europeo hay que recordar que consiguió, sin recurrir a las armas, parar la petición efectuada por Alfonso de Robray, gobernador de Navarra, en nombre del rey Felipe IV de Francia, que también lo era de Navarra, para que la frontera del viejo reino pirenaico se extendiera hasta Atapuerca, cerca ya de Burgos $^{79}$.

Especial significado tuvieron las relaciones de María de Molina con el papa Bonifacio VIII y que ponen bien de relieve el prestigio internacional de que gozaba la reina, y del que tuvo que hacer uso para conseguir las costosas y ansiadas bulas de legitimación de su matrimonio con Sancho IV: «Ca este papa Bonifacio amábala e presciábala mucho, e decía que señaladamente las gracias que él facía que las facía a la Reina, e que por ella las facía al Rey su fijo e a los otros sus fijos; e además fízole otra gracia: que las tercias de las iglesias que tomara el rey don Alfonso, e el rey don Sancho, e el rey don Fernando su fijo, sin mandado de la Iglesia de Roma fasta entonce, que gelas quitaba todas, e demás que gelas daba por tres años de allí adelante; e envió desir a la Reina que en cuanto él fuese vivo, que punase en le demandar las gracias que quisiese, que cierta fuese que gelas daría;e la noble Reina gradescióselo mucho a Dios»80.

Ya entrando, por último, en un plano más íntimo y familiar, se puede decir que María de Molina fue capaz de mantener, no sin ciertos altibajos, unas buenas relaciones con su nuera, la reina Constanza ${ }^{81}$. Por ejemplo, tuvieron sus diferencias a raíz del nacimiento de Alfonso XI sobre quién debía tener la crianza del niño ${ }^{82}$, y también a la hora de organizar la tutoría de Alfonso $\mathrm{XI}^{83}$. Tras la inesperada muerte en Sahagún de la reina Constanza (18 de noviembre de 1313), su suegra María de Molina se hará cargo de la crianza de su nieto Alfonso $\mathrm{XI}^{84}$, que se prolongará hasta el momento de su fallecimiento en 1321. Antes de morir, María de Molina, mostrando una vez más su plena confianza en los concejos, encomendó la crianza y custodia de Alfonso XI a los hombres buenos de Valladolid: «Et por esto mandó llamar a todos los caballeros, et Regidores, et omes bonos de la villa de Valladolit, et díxoles como ella estaba muy al cabo, et en las manos de Dios, et que su vida sería

la conquesta del regne de Múrcia per Jaume II (1296-1304)», Homenatge a la memòria del prof. Emilio Sáez. Aplec d'estudis dels seus deixebles i col.laboradors, Barcelona, Universitat-Institució Milà i Fontanals, 1989, y Organizació i defensa d'un territori fronterer: La governació d'Oriola en el segle XIV, Barcelona, Universitat-Institució Milà i Fontanals, 1990, entre otras obras de la autora.

79 «Crónica de Fernando IV», pp. 114-115 y 120-121.

80 «Crónica de Fernando IV», p. 119.

81 C. GONZÁLEZ MíNGUEZ, «Constanza de Portugal, reina de Castilla (1290-1313)», en M. I. DEL VAL VALDIVIESO y P. MARTÍNEZ SOPENA (Dirs.), Castilla y el mundo feudal. Homenaje al Profesor Julio Valdeón, Valladolid, 2009, vol. II, pp. 479-502.

82 «E teniendo que lo criaría la Reina doña María su madre, así commo él lo avía ordenado, la reina doña Constanza non lo tovo por bien, e ella dio la crianza del mozo al infante don Pedro por tal que fincase ella con él». «Crónica de Fernando IV», p. 168.

83 «Crónica de Alfonso XI», p. 176.

84 «Crónica de Alfonso XI», p. 178. 
muy poca: por tanto, que les quería dexar en su encomienda al Rey Don Alfonso su nieto, et que le tomasen et le guardasen et criasen ellos en aquella villa, et que non le entregasen a omes del mundo fasta que fuese de edad complida, et mandase por sí sus tierras et regnos; otrosí a la Infanta Doña Leonor su hermana» ${ }^{85}$.

\section{BALANCE FINAL}

Resulta sorprendente, hasta cierto punto, la rara unanimidad con que cronistas, historiadores y literatos han ensalzado la figura de María de Molina, sin duda una de las reinas más extraordinarias de toda la historia de España. Es evidente que María de Molina poseía unas innatas condiciones para la política y que supo moverse con acierto en medio de una coyuntura ciertamente muy complicada, influyendo de manera muy notable en el gobierno de Castilla, que en numerosas ocasiones estuvo bajo su entera responsabilidad. El objetivo último de su política fue siempre muy claro: "guardar al Rey de peligro e la tierra de guerra e de daño»86.

En efecto, María de Molina se movió en todos sus actos con una única y clara finalidad: conservar el trono castellano para su hijo y, posteriormente, para su nieto. El grandísimo valor de este objetivo esencial sirvió para que no tuviera inconveniente en llegar a todo tipo de acuerdos y en emprender complejas negociaciones, ya fuera con los nobles o con los monarcas vecinos, pero teniendo siempre presente un alto concepto del poder y de la dignidad reales. La hábil práctica de la prudencia, de la concordia o de la pacificación fueron así herramientas inexcusables para la consecución de ese objetivo superior.

Un aspecto interesante sería indagar cómo se fue construyendo en María de Molina ese talante conciliador, en el que pudieron influir determinados elementos de genética cultural e incluso ciertas influencias del franciscanismo, aunque parece que la reina simpatizaba más con la orden dominicana. Entre los pocos datos conservados de los primeros años de María de Molina destaca el nombre de su ama, María Domínguez, y el de su aya, María Fernández Coronel, mujer de temple y de probada lealtad que acompañará siempre a la reina ${ }^{87}$.

Sin duda, fue una mujer preocupada por la cultura, interés que compartiría con Sancho IV, pero realmente nada sabemos de su formación intelectual, de sus libros de lectura, etc. y de la influencia que pudieran tener en el comportamiento de la reina. Ella da nombre, «molinismo», a un modelo cultural que se define en la corte de Sancho IV, pero que adquirirá su verdadero sentido a la muerte del rey, cuando María de Molina alcanza un indiscutible protagonismo político, luchando contra las ambiciones y recelos de nobles y parientes, y trata de llevar a la práctica

85 «Crónica de Alfonso XI», p. 192.

86 «Crónica de Fernando IV», p. 193.

87 M. GAIBROIS, María de Molina..., p. 20.

${ }^{88}$ F. GÓMEZ REDONDO, Historia de la prosa medieval castellana. Il. El desarrollo de los géneros. La ficción caballeresca y el orden religioso, Madrid, 1999, p. 1225. 
un pensamiento político cuyas ideas esenciales son anteponer a Dios sobre todas las cosas, esforzarse en acabar las buenas obras y guiarse por el seso natural ${ }^{88}$.

La habitual utilización de procedimientos convencionales de «no violencia» no debe llevarnos a una conclusión equivocada en el sentido de afirmar que María de Molina fuera una mujer cobarde o débil, pues aunque personalmente no dirigiera la guerra no dejó de utilizar este medio en algunas ocasiones, como cuando ordenó el asedio de Juan Núñez de Lara en Tordehumos, y no se trata de un ejemplo aislado.

Fue una gran administradora, y así se lo reconocieron sus propios enemigos, y en todo momento se preocupó por sacar adelante la hacienda regia: «la noble reina doña María traía la facienda del Rey su fijo tan bien e tan cuerdamente e con tan gran recabdo» ${ }^{89}$. Podemos afirmar también que aunque generosa con los demás, pues no tuvo más remedio que desprenderse de muchas villas y rentas para conseguir el apoyo de los nobles, hasta enajenar prácticamente todo su patrimonio ${ }^{90}$, también es cierto que tuvo especial cuidado en rehacerlo cuando se presentó la primera oportunidad ${ }^{91}$, después del fallecimiento del infante don Enrique (11 de agosto de 1303) ${ }^{92}$, y en este sentido su comportamiento no fue muy distinto al de otros miembros de la alta nobleza demandando su parte sobre las rentas de la monarquía ${ }^{93}$. Desde luego la imagen de absoluta pobreza que presenta María de Molina cuando el cronista dice que «non fincó con ella más de un vaso de plata con que bebía, e comía en escudillas de tierra» ${ }^{94}$, no deja de ser un tanto tópica y probablemente falsa, acaso un simple recurso retórico que contribuía a la propia exaltación de la reina y que servía para subrayar la honradez de su gestión económica, denunciada precisamente en las Cortes de Medina del Campo de 1302 por el infante don Juan y por don Juan Núñez de Lara95.

89 «Crónica de Fernando IV», p. 110.

90 «E en todos estos fechos e en estas guerras la Reina avía de facer grandes costas, non aviendo ella ninguna renta de la tierra, ca todo lo tenía el infante don Enrique e Don Diego e los otros ricos omes e caballeros que servían al Rey; e avía de dar de cada día a don Diego e a los otros ricos omes que estavan con él en Valladolid dos mill maravedís para que se mantuviesen e que se non partiesen del Rey; e otrosí avía a dar grand algo a los caballeros que enviaba a las fronteras a todas partes do entendía que cumplían para guardar las villas e los castillos e todas las otras fortalezas porque se non perdiesen; e otrosí avía a dar a almogávares e a otros omes de guerra que lo avían menester; e demás desto avía a dar mucho a menudo muchos caballeros que le demandaban los caballeros, commo quier que muy pocos les mataban en la guerra, mas non podía escusar de lo facer. E estando ella muy pobre por todas estas cosas...». «Crónica de Fernando IV», p. 104.

91 «E después desto fabló la Reina con el Rey, e mostrole e commo de las rentas que eran suyas, que le diera el rey don Sancho, que la menguaban trescientos e cincuenta mill maravedís cada año; $e$ todo esto que lo diera ella en tiempo de la guerra por su servicio del; e pues que de lo que tenía de don Enrique non le diera ninguna cosa, que le demandaba esto que le menguaba; e el Rey diole en Segovia los servicios por docientas veces mill maravedís, e la martiniega con el portazgo, e los derechos por treinta mill maravedís, e prometiole que de lo primero que vacase, que le compliría lo que menguaba; e la Reina fue ende pagada». "Crónica de Fernando IV», p. 133.

92 C. GONZÁLEZ MíNGUEZ, Fernando IV de Castilla..., pp. 162-163. 325.

93 M. A. LADERO QUESADA, Fiscalidad y poder real en Castilla (1252-1369), Madrid, 1993, p.

94 «Crónica de Fernando IV», p. 125.

95 C. GONZÁLEZ MíNGUEZ, Fernando IV de Castilla..., pp. 130-133. 
En resumen, podemos afirmar que María de Molina fue una mujer que tenía lo que llamaríamos hoy un gran sentido de Estado y de la dignidad real y excepcionalmente dotada para la acción política. Hábilmente supo utilizar sus grandes armas, la prudencia y la concordia, para salvar el trono de su hijo Fernando IV y el de su nieto Alfonso XI, buscando siempre el punto de equilibrio entre la llamada «nobleza vieja» ${ }^{96}$, ahora en la cima de su poder, y los concejos, reforzados en su protagonismo político por la constitución de hermandades y su activa participación en las Cortes, que en estos años se reunieron con extraordinaria frecuencia ${ }^{97}$.

La tradición literaria e historiográfica sobre María de Molina no deja resquicio alguno para hacer la más leve crítica a su figura. ¿Fue María de Molina tan perfecta en la realidad como lo es la imagen que se ha construido sobre ella? Evidentemente, a partir de los datos de que disponemos se nos hace difícil contradecir semejante imagen, y, desde luego, su comportamiento político es verdaderamente excepcional e intachable, pero ¿cabía otra estrategia distinta de la empleada para asegurar el trono de Fernando IV y de Alfonso XI?

Un último aspecto a destacar, acaso anecdótico. Suele ser frecuente que los cronistas para exaltar las virtudes de una mujer remarquen que actuaba o valía tanto como un hombre. Nada de esto aparece en las referencias cronísticas consultadas sobre María de Molina, donde siempre se la dibuja con delicadeza y manifestando una exquisita feminidad, tanto como esposa o como madre. Tan sólo en una ocasión, como ya he señalado, se dice de ella que su espíritu hubiera sido «labrado en el yunque y oficina de los Héroes», y el héroe siempre es un personaje extraordinario pero masculino.

96 S. DE MOXÓ, «De la nobleza vieja a la nobleza nueva. La transformación nobiliaria castellana en la Baja Edad Media», Cuadernos de Historia, III (1969), pp. 1-209.

97 C. GONZÁLEZ MÍNGUEZ, «La participación concejil en la estructura de poder de la Corona de Castilla durante el reinado de Fernando IV (1295-1312)», en F. FORONDA y A. I. CARRASCO MANCHADO (Dirs.), El contrato político en la Corona de Castilla. Cultura y sociedad políticas entre los siglos $X$ al XVI, Madrid, 2008, pp. 97-121. 